\title{
Localized Hepatosplenic Sarcoidosis with an Elevated Serum CA-125 Level
}

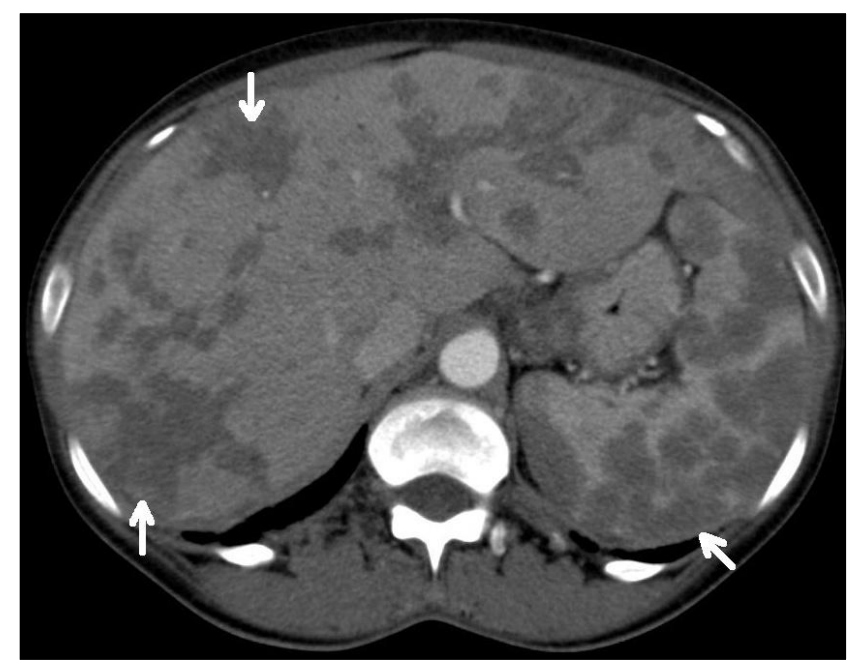

FIGURE 1. CT abdomen with contrast. Arrows indicate irregular hypoattenuating masses in the liver and spleen.

Ramin S. Herati, Joyce M. Koh, and Emmanuel C. Gorospe* Department of Medicine, Johns Hopkins Bayview Medical Center, Johns Hopkins University School of Medicine, Baltimore, MD

E-mail: egorosp1@jhmi.edu

Received January 7, 2010; Accepted February 8, 2010; Published February 17, 2010

KEYWORDS: sarcoidosis, CA-125 antigen

Sarcoidosis is a multisystem disease that is characterized by noncaseating epithelioid granulomas. Extrapulmonary sarcoidosis in addition to pulmonary involvement has been well described and occurs in $50 \%$ of patients. However, sarcoidosis without any pulmonary involvement is uncommon[1]. Cancer Antigen 125 (CA-125) is a tumor marker that is associated with ovarian malignancy. Sarcoidosis with elevated serum CA-125 has only been reported five times in the literature[2]. When sarcoidosis occurs in the absence of pulmonary involvement with elevated serum CA-125, it may mimic the presentation of disseminated ovarian carcinoma. This abdominal CT scan (Fig. 1) is from a 49-year-old, African American female with no known medical comorbidities, who presented with subjective chills and 20-lb weight loss in 6 months. She was found to have hepatomegaly, but no jaundice or stigmata of chronic liver 


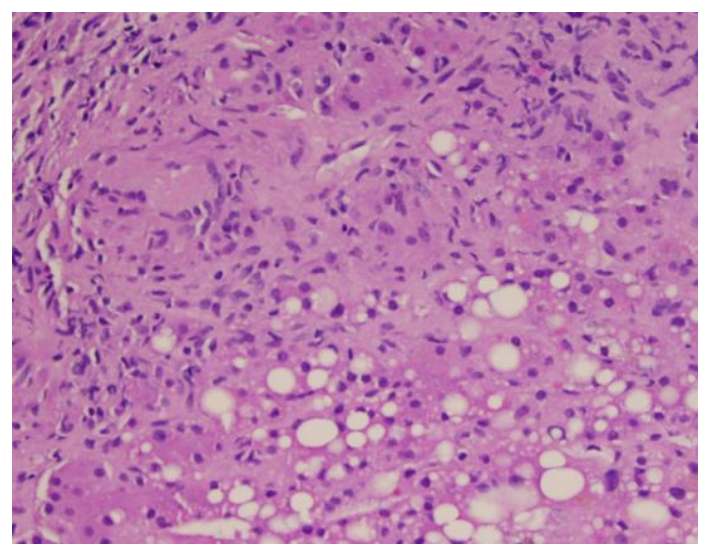

FIGURE 2. H\&E section of the liver biopsy demonstrating granulomas (arrow) with elongated histiocytes and multinucleated giant cells.

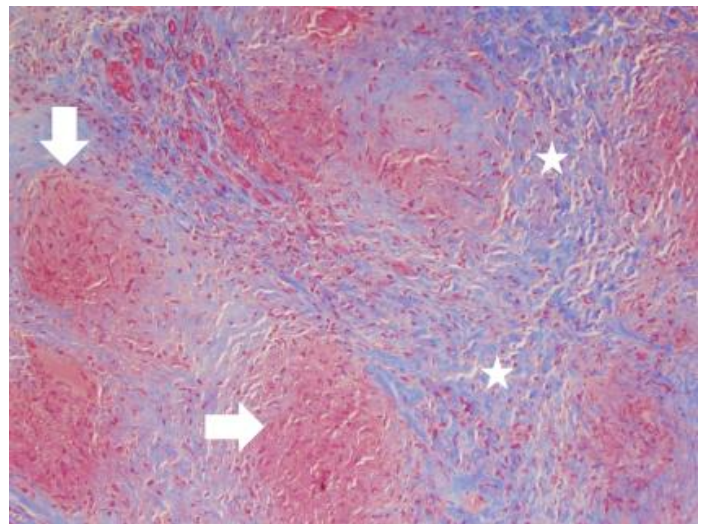

FIGURE 3. Masson stain of the liver biopsy showing areas of granulomas (arrows, in red-stained area) surrounded by fibrosis (stars, in blue-stained region).

disease. Laboratory studies showed: alanine aminotransferase $45 \mathrm{U} / \mathrm{L}$, aspartate aminotransferase $76 \mathrm{U} / \mathrm{L}$, alkaline phosphatase $533 \mathrm{U} / \mathrm{L}$, and gamma-glutamyltranspeptidase $513 \mathrm{U} / \mathrm{L}$. ACE (angiotensinconverting enzyme) level was elevated at $131 \mathrm{IU} / \mathrm{L}$, as was CA-125 at $138 \mathrm{U} / \mathrm{ml}$ (normal range: 0-35 $\mathrm{U} / \mathrm{ml}$ ). Work-up for viral hepatitis and infectious etiology was unremarkable. Flow cytometry did not reveal any evidence of lymphoma. Abdominal and chest CT scan showed diffuse areas of hypoattenuation in the liver and spleen. Endovaginal ultrasound did not show signs of ovarian malignancy. Adenopathy was present in the retroperitoneum, but not in the thorax or pelvis. Liver biopsy revealed extensive areas of fibrosis with multiple epithelioid cell granulomas (Figs. 2 and 3), consistent with sarcoidosis. In our review of the current literature, this is the first reported case of localized hepatosplenic sarcoidosis with associated serum CA-125 elevation.

\section{ACKNOWLEDGMENT}

The authors would like to thank Dr. Mostafa Fraig of The Johns Hopkins Department of Pathology for the photomicrographs. 


\section{REFERENCES}

1. Vannozzi, G., Tozzi, A., Chibbaro G., et al. (2008) Hepatic and mesenteric sarcoidosis without thoracic involvement: a case of severe noncirrhotic portal hypertension and successful pregnancy. Eur. J. Gastroenterol. Hepatol. 20, 10321035.

2. Kalluri, M. and Judson, M. (2007) Sarcoidosis associated with an elevated serum CA 125 level: description of a case and a review of literature. Am. J. Med. Sci. 334, 441-443.

\section{This article should be cited as follows:}

Herati, R.S., Koh, J.M., and Gorospe, E.C. (2010) Localized hepatosplenic sarcoidosis with an elevated serum CA-125 level. TheScientificWorldJOURNAL 10, 298-300. DOI 10.1100/tsw.2010.36. 


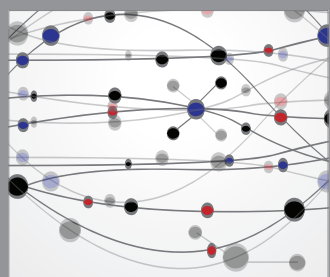

The Scientific World Journal
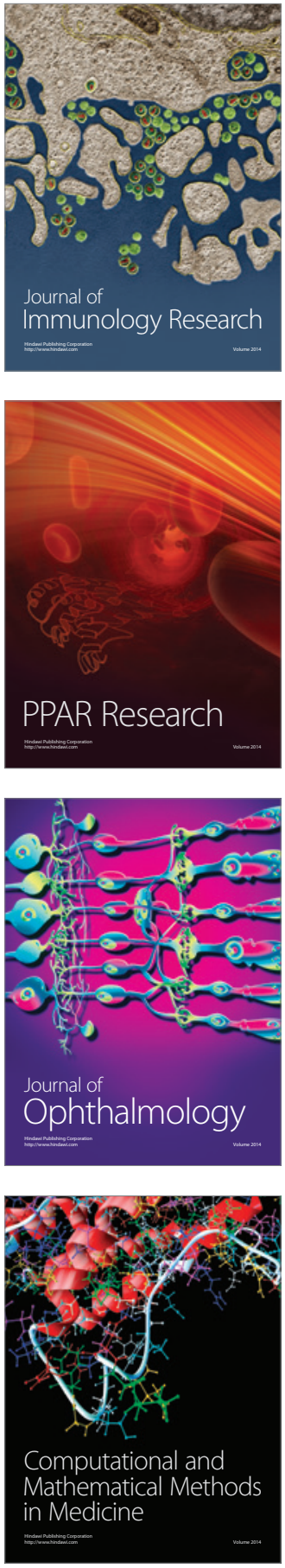

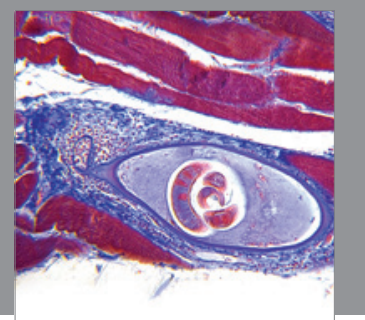

Gastroenterology

Research and Practice
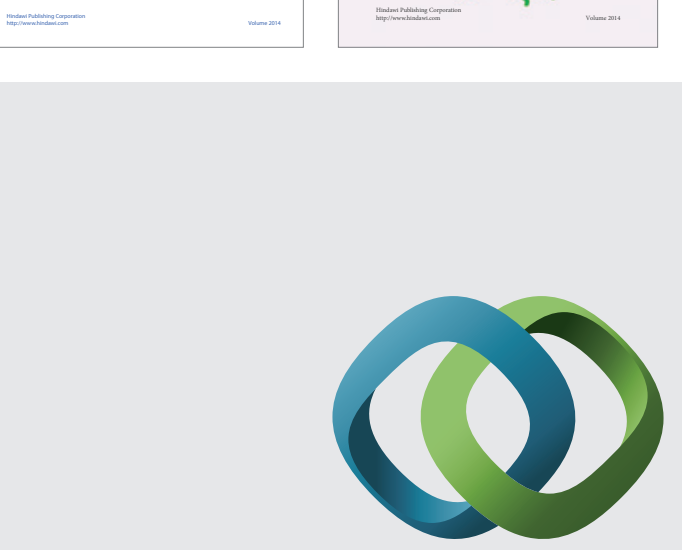

\section{Hindawi}

Submit your manuscripts at

http://www.hindawi.com
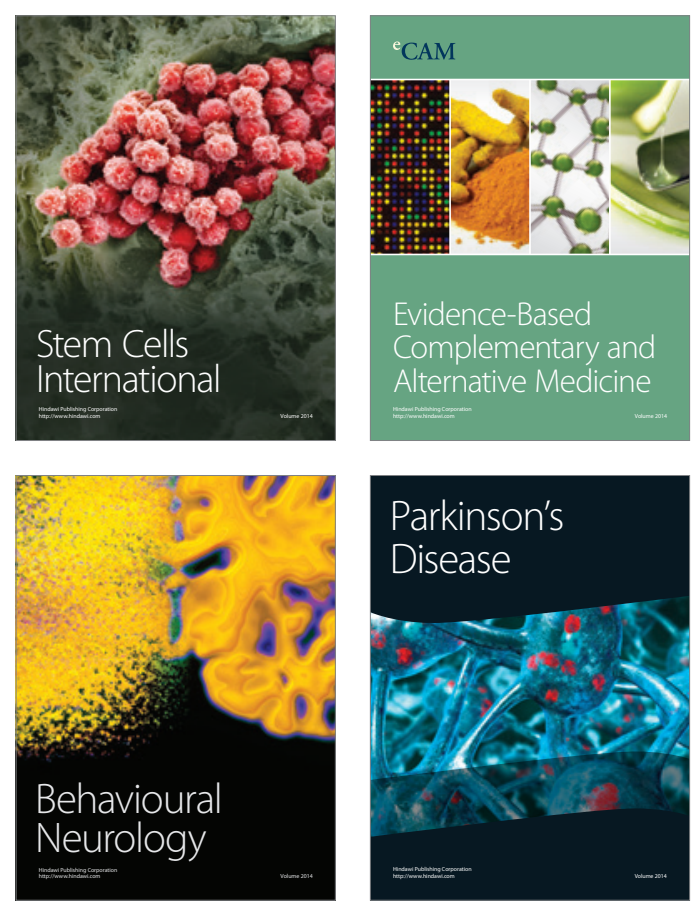

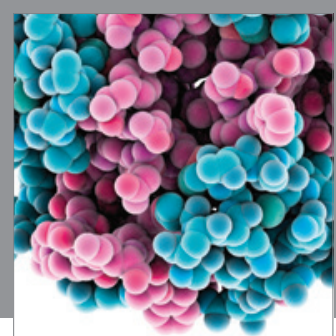

Journal of
Diabetes Research

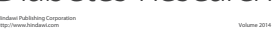

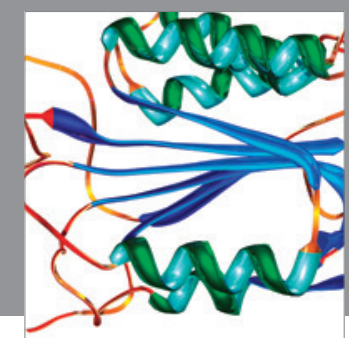

Disease Markers
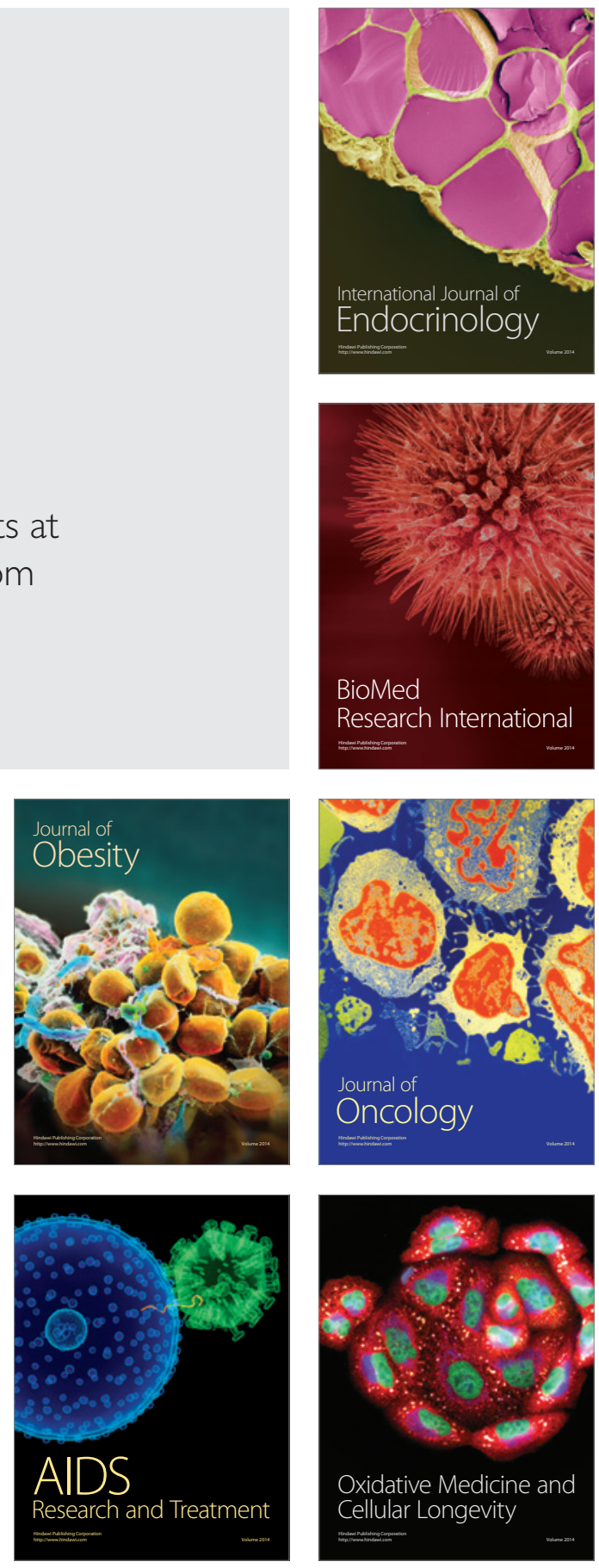